\title{
A RARE CASE OF VIRILIZING ADULT GRANULOSA CELL TUMOR
}

\author{
Dawka K. \\ Joshi $S^{3}$ \\ Bajpai S. ${ }^{4}$ \\ Gupta A. ${ }^{2}$ \\ Basi H. S.
}

\section{ABSTRACT:}

A twenty eight year old lady, married for two years with no issue, presented at Western Regional Hospital Pokhara on $8^{\text {th }}$ July, 1999 with a history of amenorrhea for $1 \frac{1}{2}$ years, lump abdomen 1 year, hoarseness of voice for 1 year and signs of hirsutism for the same duration. She was taken up for laparotomy wherein a left ovariectomy with salpingectomy was done and a large cystic ovarian tumor was removed. Post operative period was uneventful and she was advised follow up. The histopathological diagnosis was Adult Granulosa Cell Tumor. What made this case interesting is that most Granulosa Cell Tumors (about $3 / 4^{\text {th }}$ ) are estrogenic or feminizing, but rare examples, including a disproportionate number of large thin walled cystic tumors are androgenic. This was one of those rare virilizing tumors with classical features of infertility, amenorrhea, hoarseness of voice, clitiromegaly, and breast atrophy, but we could not estimate testosterone levels due to lack of facilities available.

Key Words: Granulosa Cell Tumor, Virilizing Ovarian Tumors, Sex Cord stromal tumors.

\section{INTRODUCTION:}

Sex cord stromal tumors account for approximately $6 \%$ of all ovarian tumors and for most of clinically functioning ovarian tumors. They may differentiate into ovarian type cells (granulosa cells, theca cells) or towards testicular type cells (sertoli cells, leydig cells); and occasionally intermediate in type. Granulosa cell tumors account for $1.5-2 \%$ of all ovarian neoplasms. Granulosa cell Tumors which secrete estrogen are seen in women of all ages. They are found in prepubertal girls in $5 \%$ of cases; $2 / 3^{\text {rd }}$ are in the postmenopausal age group and the remainder in women during their reproductive age.

1. M.D., D.N.B. Obstetrics \& Gynecology), Asst. Pro. Obs. \& Gyn., Manipal College of Medical Sciences Pokhara, Nepal.

2. M.D. (Pathology), Asst. Pro. Pathology, Manipal College of Medical Sciences Pokhara, Nepal.

3. M.D., M.S. (Obstetrics \& Gynecology), Medical Officer, Western Regional Hospital Pokhara, Nepal.

4. M.D. (Obstetrics \& Gynecology), Lecturer Obstetrics \& Gynecology, Manipal College of Medical Sciences Pokhara, Nepal. 5. M.B.B.S. Intern, Manipal College of Medical Sciences Pokhara, Nepal.

Address for correspondence : Dr. Kaveeta Dawka, Asst. Pro. Dept. of Obstetrics \& Gynecology

Manipal College of Medical Sciences

P.O. Box: 155, Pokhara, Nepal.

Tel: 00977-61-21012, Fax: 00977-61-22160

JNMA, October-December, 2000, 39 
They are bilateral in $2 \%$ of cases and range from a few millimeters to $20 \mathrm{~cm}$ in diameter and have a smooth lobulated appearance. ${ }^{1}$ Approximately 3/ 4ths of Granulosa cell tumors are estrogenic but rare examples including a disproportionate number of large thin walled cystic tumors are androgenic. ${ }^{2}$ Virilizing Granulosa cell tumors are uncommon and have not been well studied endocrinologically. ${ }^{3}$ Apart from endocrine symptoms patients usually present with abdominal swelling or pain.

\section{Fig. 1}

Depending on the microscopic appearance, there are two types of Granulosa cell tumors, adult type ${ }^{4}$ and juvenile type. ${ }^{5}$ It is observed however that these microscopic characteristics, although largely age dependent, are not exclusively so and overlapping patterns between the two are encountered. When Granulosa cell tumors occur in pre-pubertal girls they are associated with isosexual pseudo precocity in $75 \%$ cases. Granulosa cell tumors are almost always stage I and less than 5\% bilateral.

\section{CLINICAL PRESENTATION AND HISTORY:}

Mrs. C.J. 28 years of age, married for two years presented with a mass in the abdomen for 1 year duration, amenorrhea for $1 \frac{1 / 2}{2}$ years, hoarseness of voice \& signs of hirsutism for 1 year. She had no history of use any form of contraception but had failed to conceive in her two years of marriage. There was no pain associated with the mass. Menstrual cycles prior to $1 \frac{1 / 2}{2}$ years were normal. The patient does not smoke cigarettes nor does she consume alcohol. She had been shaving her facial hair for the past 1 year off and on. On examination, there was a growth of hair on the face and above the upper lip as well as the neck area. General examination was otherwise normal. There was definite hoarseness of voice and breast atrophy. Clitoromegaly was also apparent.

On examination of the abdomen, there was a cystic mass about the size of an 18 week gravid uterus. with side to side and slight up and down mobility, more on the left side. It was smooth in outline, cystic in consistency and non-tender. Per vagina examination revealed uterus of normal size and the mass could be felt separately from the uterus. A diagnosis of left-sided ovarian tumor was made.

\section{INVESTIGATIONS:}

Hb: $14.4 \mathrm{gm} . \%$

Bld group: A positive

BT: 2min, 6sec

CT: $5 \mathrm{~min}, 8 \mathrm{sec}$.

Urine R.E. normal

WBC: $8,800 /$ cumm

DLC: N-68 L-30 E-0

ESR: 4

Blood Urea: $20 \mathrm{mg} \%$

Creatinine: $1.5 \mathrm{mg} / \mathrm{dl}$

Chest X-Ray \& ECG: NAD

Ultrasonography: Showed features of left ovarian tumor

Fig. 2

\section{TREATMENT:}

Laparotomy was done on $18^{\text {th }}$ July 1999. Left 
ovariectomy with salpingectomy was done with removal of a large cystic tumor.

Fig. 3

\section{OPERATIVE FINDINGS:}

Uterus was normal as was the right tube and ovary. Left ovary was enlarged to about $14 \mathrm{cmX} 12 \mathrm{~cm}$; surface was smooth with no adhesions. It was cystic in nature. On cutting the specimen straw colored fluid came out (1.5-2L)

Postoperative period was uneventful and she was discharged on $26^{\text {th }}$ July, 1999 and advised to follow up.

\section{BIOPSY REPORT:}

Report no. 1253/99 Manipal College of Medical Sciences, Pathology Department.

Impession: Adult Granulosa Cell Tumor

\section{GROSS FINDINGS:}

Specimen consists of cut open oophorectomy specimen with fallopian tube. The cyst measures $14 \mathrm{~cm}$ in diameter. Cut surface shows one large cyst about $14 \mathrm{~cm}$ in diameter with a smooth inner surface and multiple multiloculated cysts in the thick fibrous wall.

\section{MICROSCOPIC FINDINGS:}

Shows sections of fallopian tube and cyst wall. The fallopian tube is unremarkable. The epithelium of the cyst lining is attenuated. The wall is composed of thick fibro-collagenous material embedded in which are multiloculated cystic areas lined by sheets of pale oval cells haphazardly arranged with scanty cytoplasm, uniform nuclei and some cells have vacuolated cytoplasm.

\section{DISCUSSION:}

The patient presented with a lump in the abdomen, she was also found to be infertile, have hirsutism, hoarseness of voice, and clitoromegaly. All these point to a virilizing ovarian tumor. These signs and symptoms should regress after removal of the tumor, but hoarseness of voice tends to remain and gross clitoromegaly may require partial reduction. The biopsy demonstrates that the tumor is found to be an Adult Granulosa Cell Tumor. Granulosa Cell Tumors are mostly estrogenic but rare cystic varieties may be androgenic. ${ }^{6}$ This case is presented on account of it being a rare virilizing form of Adult Granulosa Cell Tumor. The patient has not yet come for follow up.

\section{REFERENCES:}

1. Novaks textbook of Gynecology.

2. Norris HJ, Taylor HB- Virilization associated with cystic granulosa cell tumors Obstetrics \& Gynecology 1969; 34: 629-635.

3. Paediatrician (Bucur) 1990; 45/(2): 105-7. Gluntole RL Celebre JA Wulh, Wheeler JE, Mikuta JJ "Androgenic function of a granulosa cell tumor".

4. Principles of Surgical Pathology Stephen Sternburg Vol.II pg.2229-2231.

5. Stenwig JT, Hazekamp J.T. Beecham JB Granulosa cell tumors of the ovary a clinicopathologic study of 118 cases with long term follow up. Gynecology Oncology 1979; 7:136.

6. RE Scully, Ovarian Tumors- a review Am Journal Pathology Vol.87 pg.686-720, 1972. 